\title{
Benchmarks for Academic Oncology Faculty
}

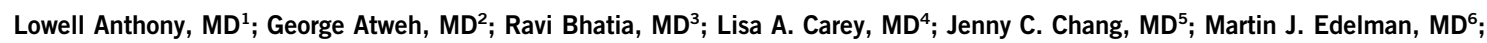

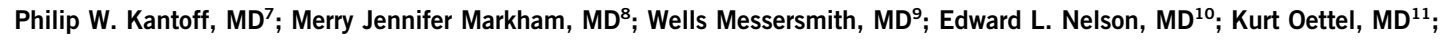
Ruth O'Regan, MD'12; Claire F. Verschraegen, $\mathrm{MD}^{13}$; and Julie M. Vose, MD ${ }^{14}$

The role of clinical researchers is vital to cancer progress. The teaching, research, and leadership roles that academic oncologists hold need to be accounted for and appropriately compensated. National metrics are currently inexistent, but are necessary to move the oncology research field forward. Clinical research and routine clinical care must be harmoniously integrated without competing. This article reviews the national landscape of clinical cancer research and proposes a call for action.

JCO Oncol Pract 17:e440-e444. ๑ 2020 by American Society of Clinical Oncology

\section{CANCER CLINICAL RESEARCH CHALLENGES}

In the last 30 years, cancer biology discoveries have led to improved patient care. These advances stem from clinical research mainly performed at academic centers. Clinical trial portfolios require substantial research and administrative time. ${ }^{1}$ This effort is directly related to patient care, but not clinically benchmarked. Academic medical oncologists face the challenge of adapting to compensation models, ${ }^{2}$ usually measured in relative value units (RVUs) and developed wholly on benchmarks based on patientfacing clinical work, ${ }^{3}$ which limits time and effort for non-RVU-generating academic activities. Clinical research effort has no standardized measure to support salaries of physicians conducting clinical research.

In June 2019, ASCO invited oncology division chiefs and department chairs to meet to exchange ideas and

Author affiliations and support information (if applicable) appear at the end of this article.

Accepted on August 27,2020 and published at ascopubs.org/journal/ op on September 30, 2020: DOI https://doi. org/10.1200/OP.20. 00020 management strategies. Among the issues identified was a high degree of heterogeneity in how institutions handled clinician workload. There was significant variation in expected number of clinic sessions and inpatient service time, RVU benchmarks, and support for non-RVU-generating clinical work. The current trend of academic centers competing with private hospitals further encroaches on the research mission. Lack of benchmarks for the academic mission was uniformly perceived as affecting physician work/life balance and burnout ${ }^{4-6}$ and highlighted the need for national standards.

\section{PHENOTYPES OF CLINICIANS IN ONCOLOGY}

Fourteen participating leaders reviewed the current state within their institutions. These leaders represented medical oncology divisions and departments across the United States, from community-based practices to university-based matrix or free-standing National Cancer Institute ( $\mathrm{NCl}$ ) -designated cancer centers. $^{7}$ Three main phenotypes of medical oncology faculty were apparent:

1. Clinicians: physicians both in private practice models and academic oncologists, whose primary focus is patient care. These are typically fulltime clinicians with little educational or research responsibilities, who may enroll patients in clinical trials.

2. Clinical researchers: academic physicians, who have significant patient care and clinical trial responsibility (design, oversight, accrual, analysis, presentation, and publication). Clinical researchers may also conduct other kinds of research (epidemiology, health service). Although research is usually funded by grants or contracts, the funding rarely supports the investigator salary.

3. Physician scientists: academic physicians, who have peer-reviewed funding and spend the majority of their time on non-patient-facing research (eg, laboratory-based, population sciences, or other health services research). They see patients to a smaller extent and may or may not be involved in clinical trials. Peer-reviewed research 
TABLE 1. Summary of the Clinical Workload by Physician Category

Community

\begin{tabular}{lccc}
\hline Outpatient sessions $^{\mathrm{a}}$ & $8-9$ & NA & NA \\
\hline Inpatient weeks $^{\mathrm{b}}$ & $0-6$ & NA & NA \\
\hline Academic & & & \\
\hline Outpatient sessions (median) $^{\mathrm{a}}$ & $6-9(8)$ & $4-6(4)$ & $0.5-2(2)$ \\
\hline Inpatient weeks (average) $^{\mathrm{b}}$ & $0-6$ & $2-12(5)$ & $0-4$
\end{tabular}

Abbreviation: NA, not applicable.

ane outpatient session, 4 hours per week.

'Inpatient, weeks per year.

funding supports a percentage of their salary, often with an institutional cost-share mechanism.

Table 1 summarizes the clinical roles played by these physicians and highlights heterogeneity. At communitybased centers, clinicians are typically full-time physicians (6-9 clinic sessions per week; median, 8 sessions) with salaries linked to clinical productivity (Table 2). These physicians generally see a mixture of tumor types and benign hematology. Academic efforts are possible by approval, with hours deducted from outpatient expectations, sometimes leading to reduced salary. At all academic centers, the three phenotypes were recapitulated. The clinician phenotype resembles community practice. Physician scientist research efforts are funded by grants or other research mechanisms, with cost-share above the National Institutes of Health salary cap generally covered by the cancer center; these physicians have fewer clinical duties (approximately $25 \%$ of full-time clinical equivalent [CFTE], with a median of 1 clinic per week; range, 1-2 sessions). In contrast, for clinical researchers, the greatest variability in clinical sessions was observed.

\section{CLINICAL RESEARCHER DILEMMA}

This article addresses the lack of appropriate metrics and support for the clinical research phenotype. For clinical researchers, the median time dedicated to clinical duties is approximately $50 \%$ (range, $40 \%-80 \%$ ) of the cFTE. Notably, the percentage of the CFTE of clinical researchers

TABLE 2. RVUs and Salary Benchmarks From 2016 to 2018

\begin{tabular}{lll}
\hline AAMC/CPSC & & \\
\hline Medical oncology & & $158,000-231,000$ \\
\hline 10th & 2,500 & $247,000-355,000$ \\
\hline 50 th & 4,900 & $450,000-473,000$ \\
\hline 90th & 8,500 & \\
\hline Hematology/oncology & & $150,000-218,000$ \\
\hline 10th & 2,900 & $244,000-355,000$ \\
\hline 50 th & 5,000 & $450,000-473,000$ \\
\hline 90 th & 8,000 & \\
\hline MGMA & & 235,000 \\
\hline Medical oncology & & 410,000 \\
\hline 10th & 2,300 & 650,000 \\
\hline 50 th & 4,400 & \\
\hline 90 th & 8,700 & 310,000 \\
\hline Hematology/oncology & & 470,000 \\
\hline 10th & 2,700 & 775,000
\end{tabular}

Abbreviations: AAMC, American Association of Medical Colleges; CPSC, Clinical Practice Solutions Center; MGMA, Medical Group Management Association; RVU, relative value unit.

aRanges for assistant professor to full professor. 
does not overlap with that of clinicians or physician scientists, creating this de facto category of clinically oriented physicians dedicated to clinical research, producing valuable efforts typically not protected through grants or other mechanisms. The lack of national benchmarks to reflect clinical research, teaching, or administrative effort is a consistent challenge, because institutions use diverse sets of expectations for various activities.

There are two main RVU benchmarking categories, based on self-reported data from hospitals and practices, for clinical productivity and salary. Academic practice benchmarks are assessed by the American Association of Medical Colleges and its associated Clinical Practice Solutions Center (AAMC/CPSC) ${ }^{8}$ or by the University Health System Consortium (UHC). Private oncology practice benchmarks are provided by the Medical Group Management Association (MGMA), the American Medical Group Association, SullivanCotter, or ECG Management Consultants $^{9}$ (Table 2). Most academic practices use the AAMC/CPSC or UHC benchmarks, and community practices often use the MGMA or SullivanCotter benchmarks, but no standardization was seen among our 14 centers. Curiously, the AAMC/CPSC benchmarks calculate higher RVUs and lower salaries than the MGMA benchmarks (Table 2). This is a potential impediment to implementation of effective models for academic oncology. . $^{2,10,11}$

Medical oncology generates $30 \%$ to $50 \%$ of net hospital margins, although this is hard to quantify accurately. ${ }^{12}$ This real bottom line does not derive from RVUs generated through evaluation and management coding, which contributes on average $25 \%$ of medical oncologists' salaries ${ }^{13}$, the profit is through revenues from cancer therapies. ${ }^{14,15}$ Infrequently, when the profit goes to the cancer center, substantial funds might be available to compensate faculty clinical research efforts. More commonly, internal accounting and complicated fund flows set by administrators and senior leadership direct faculty salaries. Division chiefs or department chairs are responsible for budgets that include not only salaries but sometimes clinic management as well, over which they usually have little control. The one constant in funds flow is a transfer of dollars, using the net margins created by oncology services, to support RVU-based salaries. However, there is no consistent model of institutional support to cover clinical research time, which is a critical driver of improvements in cancer clinical care and a major attraction for patients seeking care at academic centers.

\section{NEED FOR CLINICAL RESEARCH NATIONAL BENCHMARKS}

Clinical researchers spend considerable time studying, writing, and teaching as subject matter experts within their particular tumor types and have many required activities, besides clinic visits, that are not easily accounted for in
RVU-based compensation models. Clinical research duties are varied and increase with trial complexity and volume. Clinical research is heavily regulated through the International Conference on Harmonisation Good Clinical Practice (GCP), which aligns to the Code of Federal Regulations. ${ }^{16}$ Evolving regulations and increasing regulatory burdens are imposed on investigators without compensatory resources. ${ }^{17,18}$ ASCO measured trial acuity to describe the complexity of trials, ${ }^{19,20}$ and the National Comprehensive Cancer Network published benchmarks in 2007, ${ }^{21}$ but these analyses may be outdated. In our survey, the dedicated effort needed to successfully perform all required GCP tasks ${ }^{22}$ was $40 \%$ to $60 \%$ of the CFTE. Clinical trial contracts with the commercial sector or awards from $\mathrm{NCl}$ mechanisms do not provide adequate support for clinical investigator time and effort. Furthermore, the reconciliation of clinical trial budgets is often a retrospective measure of effort already spent that does not directly compensate an investigator's time. Alternative sources of support for clinical research and clinical researchers are therefore required. If an academic medical oncology clinical researcher workforce is to be maintained to improve the outcomes of patients with cancer through research, it is critical that these efforts are appropriately recognized, measured, and compensated at all institutions. Successful support for this critical workforce requires a degree of stability and a common language of effort allocation, even as academic centers attempt to become cost competitive in an increasingly consolidated marketplace.

\section{CALL FOR ACTION}

Division chiefs and department chairs of medical oncology, connected through ASCO myConnection, started a dialogue on the need for clinical research benchmarks. The consensus was that an appropriate benchmark for clinical researchers is a partitioning between clinical care and clinical research, with at least $50 \%$ protected time for clinical research; institutional or other official support is required; and objective measures for clinical research activities are needed, given the clinical nature and uniformly recognized value of the effort in the absence of RVU attribution.

The complex business of academic medicine needs to integrate the vital role of clinical researchers and adopt metrics necessary to move the oncology research field forward without being tied to generation of RVUs. The teaching, research, and leadership roles that academic oncologists hold need to be accounted for and compensated. ${ }^{6}$ We are calling for action to develop clinical research benchmarks. ASCO is ideally positioned to help create standards aligned with funding recommendations to support clinical researchers. 


\section{AFFILIATIONS}

${ }^{1}$ Markey Cancer Center, Lexington, KY

${ }^{2}$ University of New Mexico Comprehensive Cancer Center, Albuquerque, NM

${ }^{3} \mathrm{O}$ 'Neal Comprehensive Cancer Center, Birmingham, AL

${ }^{4}$ University of North Carolina Lineberger Comprehensive Cancer Center, Chapel Hill, NC

${ }^{5}$ Houston Methodist Cancer Center, Houston, TX

${ }^{6}$ Fox Chase Cancer Center, Philadelphia, PA

${ }^{7}$ Memorial Sloan Kettering Cancer Center, New York, NY

${ }^{8}$ University of Florida College of Medicine, Gainesville, FL

${ }^{9}$ University of Colorado Cancer Center, Aurora, CO

${ }^{10}$ University of California Irvine Chao Family Comprehensive Cancer

Center, Orange, CA

${ }^{11}$ Gundersen Health System, La Crosse, WI

${ }^{12}$ Carbone Cancer Center, Madison, WI

${ }^{13}$ Ohio State University Comprehensive Cancer Center, Columbus, $\mathrm{OH}$

${ }^{14}$ University of Nebraska Medical Center, Omaha, NE

\section{CORRESPONDING AUTHOR}

Claire F. Verschraegen, Ohio State University College of Medicine, A455, Starling Loving Hall, 320 W. 10th Ave, Columbus, $\mathrm{OH} 43210$; e-mail: claire.verschraegen@osumc.edu.

\section{AUTHORS' DISCLOSURES OF POTENTIAL CONFLICTS OF INTEREST}

Disclosures provided by the authors are available with this article at DOI https://doi.org/10.1200/OP.20.00020.

\section{AUTHOR CONTRIBUTIONS}

Conception and design: All authors

Administrative support: Edward L. Nelson, Claire F. Verschraegen

Provision of study material or patients: Lowell Anthony, Martin J. Edelman, Edward L. Nelson, Kurt Oettel, Julie M. Vose

Collection and assembly of data: Lowell Anthony, Lisa A. Carey, Jenny C. Chang, Martin J. Edelman, Merry Jennifer Markham, Kurt Oettel, Claire F. Verschraegen, Julie M. Vose

Data analysis and interpretation: Lowell Anthony, George Atweh, Ravi Bhatia, Lisa A. Carey, Martin J. Edelman, Philip W. Kantoff, Merry Jennifer Markham, Wells Messersmith, Edward L. Nelson, Julie M. Vose Manuscript writing: All authors

Final approval of manuscript: All authors

Accountable for all aspects of the work: All authors

\section{REFERENCES}

1. Overhage JM, McCallie D Jr: Physician time spent using the electronic health record during outpatient encounters: A descriptive study. Ann Intern Med 172: 169-174, 2020

2. Kern S: Analytic model for academic research productivity having factors, interactions and implications. Cancer Biol Ther $12: 949-956,2011$

3. Ducatman BS, Parslow T: Benchmarking academic anatomic pathologists: The Association of Pathology Chairs survey. Acad Pathol 3:2374289516666832, 2016

4. Nowakowski J, Borowiec G, Zwierz I, et al: Stress in an oncologist's life: Present but not insurmountable-(Students should not be discouraged choosing oncology as their future specialisation). J Cancer Educ 32:198-205, 2017

5. Shanafelt TD, West CP, Sinsky C, et al: Changes in burnout and satisfaction with work-life integration in physicians and the general US working population between 2011 and 2017. Mayo Clin Proc 94:1681-1694, 2019

6. Kleiner S, Wallace JE: Oncologist burnout and compassion fatigue: Investigating time pressure at work as a predictor and the mediating role of work-family conflict. BMC Health Serv Res 17:639, 2017

7. Simone JV: Understanding cancer centers. J Clin Oncol 20:4503-4507, 2002

8. Bergen B: Vizient and AAMC launch clinical practice solutions center to drive efficiency for physician practices. https://www.aamc.org/news-insights/pressreleases/vizient-and-aamc-launch-clinical-practice-solutions-center-drive-efficiency-physician-practices.

9. Feltenberger GS, Gans DN: Benchmarking Success: The Essential Guide for Medical Practice Managers (ed 2). Englewood, CO, Medical Group Management Association, 2017

10. Primack BA, Dilmore TC, Switzer GE, et al: Burnout among early career clinical investigators. Clin Transl Sci 3:186-188, 2010

11. West CP, Dyrbye LN, Erwin PJ, et al: Interventions to prevent and reduce physician burnout: A systematic review and meta-analysis. Lancet 388:2272-2281, 2016

12. Becker's Hospital Review: 12 best practices for successful hospital oncology departments. https://www.beckershospitalreview.com/news-analysis/12-bestpractices-for-successful-hospital-oncology-departments.html

13. Balch C, Ogle JD, Senese JL: The National Practice Benchmark for Oncology: 2015 report for 2014 data. J Oncol Pract 12:e437-e475, 2016

14. Vandigo J: Patients pay the price when hospitals mark up cancer medicines. https://catalyst.phrma.org/patients-pay-the-price-when-hospitals-mark-upcancer-medicines

15. Vandervelde A, Blalock E: The Oncology Drug Marketplace: Trends in Discounting and Site of Care. https://www.communityoncology.org/wp-content/uploads/ 2017/12/BRG_COA-340B-Study_NOT_EMBARGOED.pdf

16. Barnett International: CFR ICH GCP Reference Guide 2019. https://www.barnettinternational.com/Publications/CFR/ICH-GCP-Reference-Guide-2019/

17. Stewart DJ, Whitney SN, Kurzrock R: Equipoise lost: Ethics, costs, and the regulation of cancer clinical research. J Clin Oncol 28:2925-2935, 2010

18. American Society of Clinical Oncology: The state of cancer care in America, 2017: A report by the American Society of Clinical Oncology. J Oncol Pract 13: e353-e394, 2017

19. Good MJ, Lubejko B, Humphries K, et al: Measuring clinical trial-associated workload in a community clinical oncology program. J Oncol Pract 9:211-215, 2013

20. Good MJ, Hurley P, Woo KM, et al: Assessing clinical trial-associated workload in community-based research programs using the ASCO clinical trial workload assessment tool. J Oncol Pract 12:e536-e547, 2016

21. Stewart FM, Wasserman RL, Bloomfield CD, et al: Benchmarks in clinical productivity: A national comprehensive cancer network survey. J Oncol Pract 3:2-8, 2007

22. Ambrosy AP, Mentz RJ, Krishnamoorthy A, et al: Identifying barriers and practical solutions to conducting site-based research in North America: Exploring acute heart failure trials as a case study. Heart Fail Clin 11:581-589, 2015 


\section{Benchmarks for Academic Oncology Faculty}

The following represents disclosure information provided by authors of this manuscript. All relationships are considered compensated unless otherwise noted. Relationships are self-held unless noted. I = Immediate Family Member, Inst = My Institution. Relationships may not relate to the subject matter of this manuscript. For more information about ASCO's conflict of interest policy, please refer to www.asco.org/rwc or ascopubs.org/op/authors/author-center.

Open Payments is a public database containing information reported by companies about payments made to US-licensed physicians (Open Payments).

\section{Lowell Anthony}

Research Funding: AbbVie (Inst), Oncotelic (Inst), Entrinsic Health Solutions (Inst)

\section{Lisa A. Carey}

Research Funding: Innocrin Pharma (Inst), Syndax (Inst), Immunomedics (Inst), Novartis (Inst), NanoString Technologies (Inst), AbbVie (Inst), Seattle Genetics (Inst)

Patents, Royalties, Other Intellectual Property: Royalty-sharing agreement, investorship interest in licensed IP to startup company, Falcon Therapeutics, that is designing neural stem cell-based therapy for glioblastoma multiforme (I) Uncompensated Relationships: Sanofi (Inst), Novartis (Inst), G1 Therapeutics (Inst), Genentech/Roche (Inst), GlaxoSmithKline (Inst), Exact Sciences (Inst) AstraZeneca/Daiichi Sanyo (Inst), Aptitude Health (Inst)

Open Payments Link: https://openpaymentsdata.cms.gov/physician/17967

Jenny C. Chang

Consulting or Advisory Role: Genentech, Celgene

Travel, Accommodations, Expenses: Celgene, Genentech

Martin J. Edelman

Stock and Other Ownership Interests: Biomarker Strategies, Neumedicines Consulting or Advisory Role: Eli Lilly, Bristol Myers Squibb, Boehringer Ingelheim, WindMIL, Syndax, Flame Biosciences, Precision Oncology Research Funding: Bristol Myers Squibb (Inst), Apexigen (Inst), Nektar (Inst), GlaxoSmithKline (Inst), WindMIL (Inst), United Therapeutics (Inst)

Patents, Royalties, Other Intellectual Property: Patent application for radiopharmaceutical to treat small cell lung cancer (Inst)

Travel, Accommodations, Expenses: Nektar

Other Relationship: AstraZeneca/Medlmmune, Eli Lilly, Boehringer Ingelheim, Takeda, Seattle Genetics

\section{Philip W. Kantoff}

Leadership: Context Therapeutics

Stock and Other Ownership Interests: Placon, Druggablity Technologies,

Context Therapeutics, Seer

Consulting or Advisory Role: Bavarian Nordic, Janssen, Merck, OncoCellMDX Genentech/Roche, Tarveda Therapeutics, Druggablity Technologies, Progenity, Context Therapeutics, GE Healthcare, Seer

Patents, Royalties, Other Intellectual Property: Method for predicting the risk of prostate cancer morbidity and mortality; Predicting and treating prostate cancer Methods for predicting likelihood of responding to treatment; Chromosome copy number gain as a biomarker of urothelial carcinoma lethality; Drug combinations to treat cancer; Somatic ERCC2 mutations correlate with cisplatin sensitivity in muscle-invasive urothelial carcinoma (patent); Up-to-Date royalties; Wolters
Kluwer royalties; Methods and kits for determining sensitivity to cancer treatment; Composition and methods for screening and diagnosis of prostate cancer

Open Payments Link: https://openpaymentsdata.cms.gov/physician/55315/ summary

\section{Merry Jennifer Markham}

Research Funding: Aduro Biotech (Inst), Eli Lilly (Inst), Tesaro (Inst), Novartis (Inst), VBL Therapeutics (Inst), AstraZeneca (Inst)

Open Payments Link: https://openpaymentsdata.cms.gov/physician/890992/ summary

Wells Messersmith

Consulting or Advisory Role: FivePrime Therapeutics (Inst), QED Therapeutics Research Funding: Pfizer (Inst), Roche/Genentech (Inst), OncoMed (Inst), Immunomedics (Inst), Alexo Therapeutics (Inst), Takeda (Inst), D3 Pharma (Inst), Beigene (Inst)

Open Payments Link: https://openpaymentsdata.cms.gov/physician/868582

\section{Edward L. Nelson}

Consulting or Advisory Role: Laboratory for Advanced Medicine

\section{Ruth O'Regan}

Honoraria: bioTheranostics, Pfizer, Macrogenics, Immunomedics, Genomic Health, Puma Biotechnology, Novartis, Genentech, Eli Lilly

Consulting or Advisory Role: Puma Biotechnology, bioTheranostics, Genomic Health, Novartis, Macrogenics, Immunogenics, Genentech, Eli Lilly

Research Funding: Novartis (Inst), Eisai (Inst), Pfizer (Inst), Puma Biotechnology (Inst), Seattle Genetics (Inst)

Travel, Accommodations, Expenses: Eli Lilly, Puma Biotechnology, Genomic Health, Macrogenics, Immunomedics

Claire F. Verschraegen

Consulting or Advisory Role: Celltrion

Julie M. Vose

Honoraria: Novartis, AbbVie, Vaniam Group, Janssen Scientific Affairs, Kite/ Gilead, Acerta Pharma/AstraZeneca, Verastem, Miltenyi Biotec, Loxo Oncology, Allogene, Wugene, Celgene, Roche Pakistan

Consulting or Advisory Role: Bio Connections

Research Funding: Celgene (Inst), Incyte (Inst), Acerta Pharma (Inst), Kite Pharma (Inst), Seattle Genetics (Inst), Novartis (Inst), Bristol Myers Squibb (Inst), AstraZeneca (Inst), Juno Therapeutics (Inst)

No other potential conflicts of interest were reported. 